\title{
Optimum Parametric Identification of a Stand-Alone Photovoltaic System with Battery Storage and Optimization Controller Using Averaging Approach
}

\author{
Mayouf Messaoud $^{1 *}$, Bakhti Haddi $^{2}$ \\ ${ }^{1}$ Electrical Engineering Department, Faculty of Technology, University of Msila, BP 166 Msila 28000, Algeria \\ ${ }^{2}$ Electronics Department, Faculty of Technology, University of Msila, BP 166 Msila 28000, Algeria
}

Corresponding Author Email: messaoud.mayouf@univ-msila.dz

https://doi.org/10.18280/jesa.540108

Received: 18 November 2020

Accepted: 2 February 2021

\section{Keywords:}

standalone photovoltaic (PV) system, dynamic modeling, averaging approach, linearization, stat of charge (SOC), maximum power point (MPPT), buck converter

\begin{abstract}
The dimensioning of photovoltaic systems is the major concern of researchers and power industry practitioners. This aims to improve energy efficiency and protect the conversion units by a consistent assessment of power conditioning circuits and interconnections for the PV application. In this context, this paper sets out to fulfill detailed modeling and control steps of a standalone photovoltaic (PV) power system with energy storage, according to practical specifications of the load, PV generation unit, and battery pack. The main goal is to estimate all unknown parameters, as the diode ideality factor and revers saturation current, the controller, and the PV link. The PV link interfacing the PV source circuit to the PV-side converter (PVSC) provides a filtering function to maintain a steady voltage at the link. The charge controller used in the PV-side converter is a DC/DC buck converter. It transfers the PV power to the battery and supplies the load. Using pulse- width modulation (PWM) technical, of which the switching duty cycle is the control-input variable; the PVSC power-conditioning circuit is permanently controlled by the maximum power point tracking (MPPT) algorithm to achieve the maximum energy. The battery pack voltage is properly maintained by the charge controller and specified to match the load voltage rating, to avoid a high ratio of voltage conversion. A method is proposed to integrate both the MPPT function and the battery cycle charge. The PV generator output and the power conditioning circuits, mainly constructed from switching- mode power converters, are nonlinear. An averaged model is then derived for dynamic analysis and controller synthesis, using the state-space averaging and linearization method. A PV array of nine PV modules configured into three strings is used in this application to demonstrate the effectiveness of modeling, design, control, and simulation. Simulation model for the controller and power interface is built and developed in short term, using the fundamental blocks of Matlab Simulink.
\end{abstract}

\section{INTRODUCTION}

Photovoltaic (PV) power engineering has attracted significant attention in recent years. This energy is free, clean, and permanently dispersed throughout the world, compared with exhaustible and polarizing fossil fuels [1].

In this context, our study focuses on the design, integration, and simulation of a standalone PV system with battery charging. A successful standalone photovoltaic installation requires first an energy saving approach, then a rigorous design with components that meet the needs and promises. This requires mastering the basic techniques, and concrete steps to design such a system, putting in place the main components namely, the battery, the regulator, and the converter. Taking into account the technical requirements, the system has been designed according to specific steps.

System sizing is based on a clear specification of the load profile which includes the reference nominal load voltage for rating the battery pack and solar generation unit voltages. I-V and $\mathrm{P}-\mathrm{V}$ curves are commonly used to illustrate the outputs of PV cells, modules, strings, or arrays. Computational models can be developed to represent the PV output characteristics under variations in cell temperature and solar irradiance. These models are classified according to their equivalent circuits into two main types: single-diode model (SDM) and double-diode model (DDM).

Various modeling approaches have been presented in the literature. For example, a single diode model with both parallel and series resistors was detailed [2]. The same approach was applied in several studies such as $[3,4]$. In which, these two internal characteristics are considered very important and require its judicious determination. The models designed by Zerhouni et al. [5, 6] hold only the resistance in series. The parallel resistance is considered very large and can be ignored. To simplify the model, even more, the ideal single diode model (ISDM) is chosen in this paper. Both resistances are removed by assuming that the one in series one is very small, and the one in parallel is very large. Some papers focus on the dimensioning of power converters. A full study [7] is done only, to calculate the component values of the buck converter in the PV system by the method of minimizing losses of switching devices. In our approach, we refer to the manufacturers' data at standard test conditions (STC) to specify the PV link, using the peak-to-peak values and the duty cycle operating at nominal load conditions.

Voltage regulation for the PV and DC links is introduced 
and analyzed using dynamic models that are developed based on the state-space averaging, and linearization technique. A simple practical PID regulator is therefore calculated and integrated, unlike those developed by complicated techniques, such as those developed by Precup et al. [8].

Maximum power point tracker techniques differ in several aspects as feasibility, analogical or digital realization, sensor requirements, effectiveness, rate of convergence, hardware embodiment, cost, and other aspects. The most well used are perturb and observe algorithm and incremental conductance algorithm $[9,10]$. Other papers introduce artificial intelligence techniques as used in the ref. [11, 12]. The MPPT algorithm introduced in this paper is based on the hill and climbing technique to improve tracking performance. To enhance the practicality of this paper, a specific battery module is used, where real discharge characteristics are given by the product datasheet.

It was given that the majority of papers focus their contributions on control, dimensioning, battery charging, or maximization. We have opted in this article to integrate both aspects at the same time. Simulation model for the controller and power interface is developed in short term to capture the transient details of fast dynamics and demonstrate the effectiveness of modeling, design, and control of the standalone PV power system.

\section{MODELING OF STAND-ALONE PV SYSTEM}

The equivalent circuit studied for analysis and simulation is illustrated in Figure 1. The buck converter is the charge controller that transfers the PV power to the battery and supplies the load. Battery equivalent circuit is formed by a voltage source $\mathrm{V}_{\mathrm{OC}}$ in series connection with a resistor $R_{b a t}$, and equivalent capacitance across the battery pack $C_{B A T}$. All DC loads are simplified to draw current from the battery link, which is denoted as $i_{\text {load }}$.

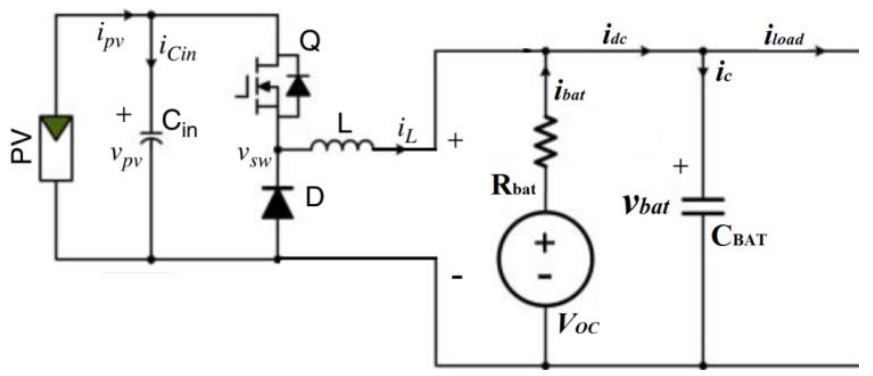

Figure 1. Equivalent circuit of the PV system

\subsection{PV cell output characteristics and mathematical models}

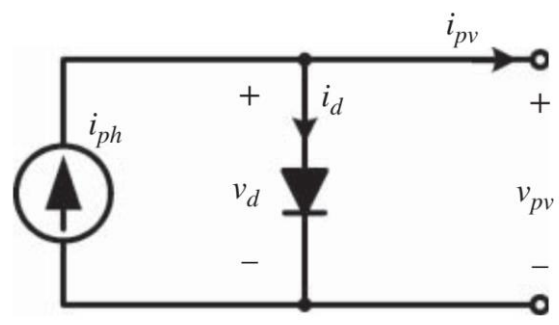

Figure 2. Scheme of PV cell with ideal single-diode model
Considering the objectives envisaged from this study, the choice of the solar panel equivalent circuit does not affect the overall behavior of the systems. Indeed, and for reasons of simplification, we chose the simplest ideal single-diode model (ISDM). Based on the p-n junction structure for both PV cell and diode, the model has only a current source in parallel with a diode, as shown in Figure 2.

For standard test conditions (STC) of cell temperature and solar irradiance, the current-voltage characteristics are expressed by Eq. (1):

$$
i_{p v}=i_{p h}-\underbrace{i_{s}\left[e\left(\frac{q v_{p v}}{k T_{c} A_{n}}\right)-1\right]}_{i_{d}}
$$

The values of the $p-n$ junction constants, model parameters, and variables are listed in Table 1 .

Table 1. PV parameters

\begin{tabular}{cc}
\hline Components & Rating values \\
\hline Irradiance at STC & $1000 \mathrm{~W} / \mathrm{m}^{2}$ \\
Boltzmann constant & $K=1.38 \times 10^{-23} \mathrm{~J} / \mathrm{K}$ \\
Electron Charge & $1.6 \times 10^{-19} \mathrm{C}$ \\
PV cell temperature at STC & $298 \mathrm{~K}$ \\
Thermal voltage of p-n junction at STC & $25.7 \mathrm{mV}$ \\
PV Cells number per module & 60 \\
PV power at MPP and STC & $280 \mathrm{~W}$ \\
PV voltage at MPP and STC & $31.67 \mathrm{~V}$ \\
PV current at MPP and STC & $8.84 \mathrm{~A}$ \\
PV open-circuit voltage at the STC & $38.97 \mathrm{~V}$ \\
PV short-circuit current at the STC & $9.41 \mathrm{~A}$ \\
Temperature coefficient on PV current & $0.04 \% /{ }^{\circ} \mathrm{C}$ \\
Temperature coefficient on PV voltage & $-0.29 \% /{ }^{\circ} \mathrm{C}$ \\
Irradiance coefficient on PV power & $-0.40 \% /{ }^{\circ} \mathrm{C}$ \\
\hline
\end{tabular}

\subsubsection{Parameters identification at STC}

When the terminal of the equivalent circuit shown in Figure 2 is shorted, the diode current $i_{d}$ is equal to zero. The value of the photon current $i_{p h}$ is equal to the short-circuit current $I_{S C S}$ which is available from the product datasheet. When the terminal is opened, the PV cell output current $i_{p v}$ is equal to zero. The value of the diode current, $i_{d}$, becomes equal to the photon current $i_{p h}$ which is the ISCS at STC. This can be expressed as in Eq. (2), which includes two unknown parameters of $I_{S s}$ and $A_{n}$ :

$$
i_{S C S}=i_{S S}\left[e^{\left(\frac{v_{O C S}}{v_{T C S} A_{n}}\right)}-1\right]
$$

where, $I_{S S}$ is the diode reverse-bias saturation current, and $V_{T C S}$ is the thermal voltage at STC, which is constant and expressed as:

$$
v_{T C S}=\frac{k T_{C S}}{q}
$$

Using Eq. (1), the I-V characteristics of the maximal power point (MPP) is, therefore, expressed in STC by Eq. (4) 


$$
i_{M S}=i_{S C S}-i_{S S}\left[e^{\left(\frac{v_{M S}}{v_{T C S} A_{n}}\right)}-1\right]
$$

The unknown parameters $i_{S S}$ and $A_{n}$ can be determined by solving the two nonlinear equations, Eq. (2) and Eq. (4). They can also be combined to form one Eq. (5):

$$
\frac{e\left(\frac{v_{M S}}{v_{T C S}} \frac{1}{A_{n}}\right)-1}{e\left(\frac{v_{O C S}}{v_{T C S}} \frac{1}{A_{n}}\right)-1}=1-\frac{i_{M S}}{i_{S C S}}
$$

We define a new variable $A_{i n v}$ as the reciprocal of $A_{n}$ :

$$
A_{i n v}=\frac{1}{A_{n}}
$$

The Eq. (5) can be reorganized as Eq. (7) which is a nonlinear equation [13]:

$$
f\left(A_{i n v}\right)=e^{C_{1} A_{i n v}}-C_{3} e^{C_{2} A_{i n v}}-1+C_{3}=0
$$

where, the constants are calculated as:

$$
\left\{\begin{array}{c}
C_{1}=\frac{v_{M S}}{v_{T C S}} \\
C_{2}=\frac{v_{O C S}}{v_{T C S}} \\
C_{3}=1-\frac{i_{M S}}{i_{S C S}}
\end{array}\right.
$$

We use the Newton-Raphson method to solve Eq. (7). The derivation of $f\left(A_{i n v}\right)$ is expressed in Eq. (9):

$$
f^{\prime}\left(A_{i n v}\right)=C_{1} A_{i n v} e^{C_{1} A_{i n v}}-C_{3} C_{2} A_{i n v} e^{C_{2} A_{i n v}}
$$

Since the values of $A_{n}$ are generally between 1 and $2, A_{\text {inv }}$ can be assigned an initial value of 0.7 . The chosen tolerance is $\left(E r r=10^{-6}\right)$. Newton-Raphson numerical iteration is given by Eq. (10).

$$
A_{i n v}(n+1)=A_{i n v}(n)-\frac{f\left[A_{i n v}(n)\right]}{f^{\prime}\left[A_{i n v}(n)\right]}
$$

The software flowchart for parameters identification is illustrated in Figure 3. The value of $A_{\text {inv }}$ is continuously updated until the output of $f\left(A_{\text {inv }}\right)$ is close to zero, and the resulting value of $A_{n}$ represents, therefore, the ISDM ideality factor.

\subsubsection{Variation with irradiance and temperature}

In reality, The I-V characteristics of the simulation model should respond to variations in both cell temperature and solar irradiance. The PV cell manufacturer usually provides correction coefficients derived from experimental evaluations.

The temperature coefficients for PV output current, voltage, and power are denoted $\alpha_{T}, \beta_{T}$, and $\lambda_{T}$, respectively.

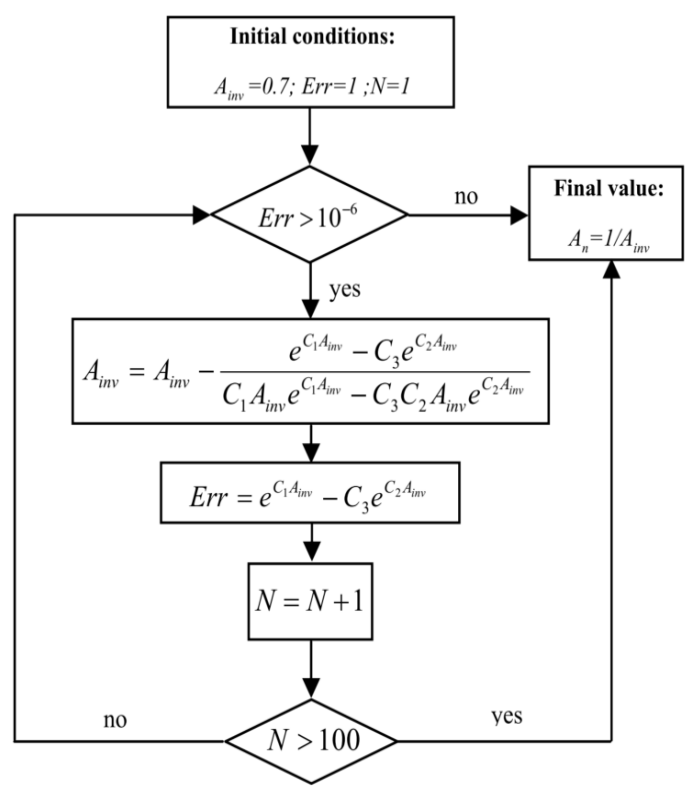

Figure 3. Flowchart of the Newton-Raphson method

Based on the assumption that the ideality factor $A_{n}$ is constant regardless of environmental variations, the expression of $i_{p h}$ should be [13]:

$$
i_{p h}(G, \Delta T)=\frac{G}{G_{S T C}} i_{S C S}\left(1+\alpha_{T} \Delta T\right)
$$

where, $G$ is the present solar radiation and $G_{S T C}$ is the solar radiation at the reference test. $\Delta T$ is the difference between the cell temperature $T_{C}$ and the temperature at STC, $T_{C S}$, which is $25^{\circ} \mathrm{C}$ or $298 \mathrm{~K}$. The open-circuit voltage correction for both solar irradiance and cell temperature variations is given by Eq. (12):

$$
v_{O C}(G, \Delta T)=v_{O C S}\left(1+\beta_{T} \Delta T\right) v_{T}
$$

The value of the diode saturation current $i_{s}(G, \Delta T)$ can be determined from open-circuit conditions, since the photon current is equal to the diode current:

$$
i_{S}(G, \Delta T)=\frac{i_{p h}(G, \Delta T)}{e^{\left[\frac{q v_{o c}(G, \Delta T)}{k T_{c} A_{n}}\right]}-1}
$$

The (I-V) characteristic equation of a PV cell with cell temperature and solar irradiance variations can be written as:

$$
i_{p v}=i_{p h}(G, \Delta T)-\underbrace{i_{s}(G, \Delta T)\left[e^{\left(\frac{q v_{p v}}{k T_{c} A_{n}}\right)}-1\right]}_{i_{d}(G, \Delta T)}
$$

The PV module voltage $V_{p v M}$ and current $I_{p v M}$ are given in term of the cell's voltage $V_{p v}$ and current $I_{p v}$ by the following relations:

$$
\begin{gathered}
I_{p v M}=N_{S} I_{p v} \\
V_{p v M}=N_{p} v_{p v}
\end{gathered}
$$


where, $N_{S}$ is the number of series cells and $N_{P}$ is the number of parallel cells. The PV cell parameters can be estimated using the specification of the PV module shown in Table 1. The PV array has a $3 \times 3$ configuration of nine PV modules. Therefore, the PV array output characteristics are represented by the (I$\mathrm{V})$ and $(\mathrm{P}-\mathrm{V})$ curves shown in Figures 4 and 5 to illustrate the impact of changes in cell temperatures and solar irradiance, respectively. With a balanced operation of nine PV modules, the MPP of the array is indicated as $2525 \mathrm{~W}$ and is at $(96.66$ $\mathrm{V}, 26.12 \mathrm{~A})$.
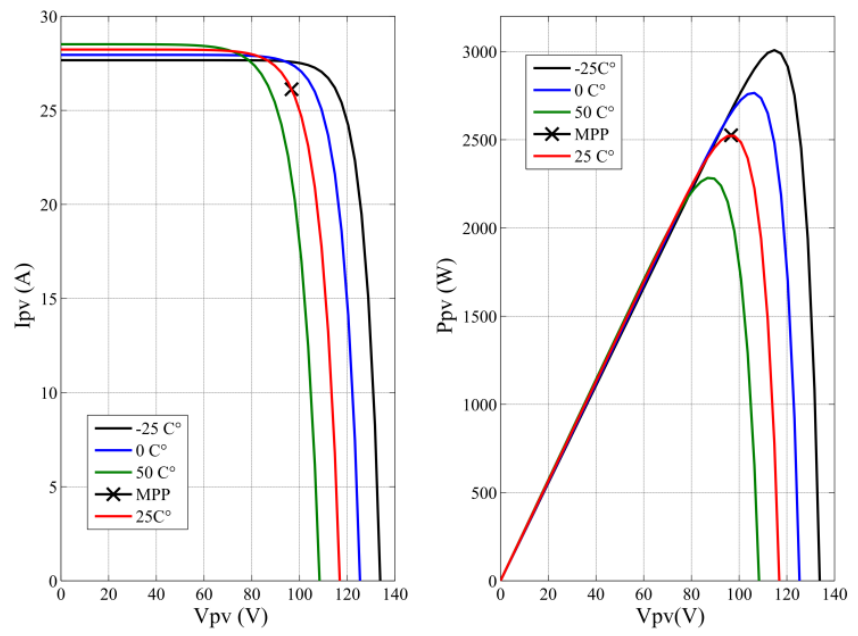

Figure 4. PV characteristics by varying temperature
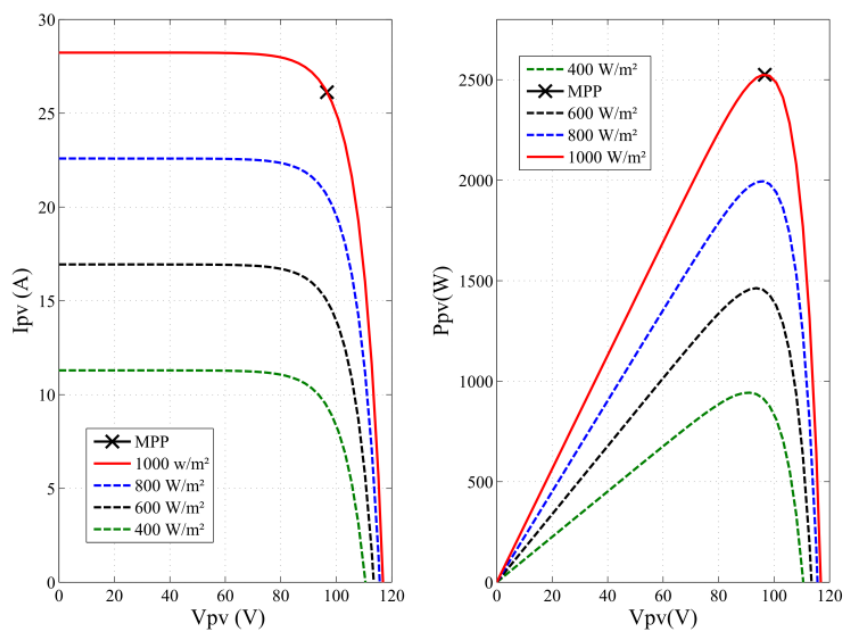

Figure 5. PV characteristics by varying irradiance

\subsection{Buck converter dimensioning}

In the PV system of Figure 1, the DC-DC buck converter is controlled using pulse width modulation (PWM) technique, in which the switching duty cycle $\mathrm{D}$ is the control-input variable. A step-down topology should be considered if the converteroutput voltage is never higher than the PV terminal voltage $V_{M P P}$, when the normal voltage variation of both sides has been considered. The condition can be expressed as $V_{O}(\max ) \leq$ $V_{M P P}(\min )$. The lowest value of the PV terminal voltage at the MPP, $V_{M P P}(\min )$, can be estimated from the highest ambient temperature and the minimum irradiance for the converter to operate. The highest value of the output voltage, $V_{O}(\max )$, can be determined from the load profile. For battery-charging applications, the battery voltage becomes the converter-output voltage $V_{o}$, which varies from the cut-off voltage at $0 \%$ state of charge (SOC) to the highest level: the open-circuit voltage at $100 \%$ SOC. In this case, the value of $V_{O}(\max )$ is equivalent to the open-circuit voltage of the battery at $100 \%$ SOC [13].

\subsubsection{Calculation of $L$ and $C_{i n}$}

At STC and the predefined switching frequency $f_{s w}$, the inductor ripple current and ripple voltage at the PV link should be specified by the peak-to-peak values, $\Delta I_{L}$ and $\Delta V_{P V}$, respectively. Steady-state analysis may determine the duty cycle at the nominal load operating condition. At STC, the PV source circuit should be operated at the MPP, which is represented by $V_{M P P}$ and $I_{M P P}$. The duty cycle can be calculated using Eq. (17):

$$
D_{0}=\frac{V_{0-N O M}}{V_{M P P}}
$$

The nominal output voltage $V_{o-N O M}$ corresponding to the buck converter in continuous conduction mode (CCM) can be specified from the load profile. The value of the inductance, $\mathrm{L}$, and the capacitance, $C_{i n}$, can be calculated from Eq. (18) and Eq. (19), respectively.

$$
L=\frac{V_{0-N O M}\left(1-D_{0}\right)}{\Delta I_{L} f_{s w}}
$$

$$
C_{i n}=\frac{I_{M P P}\left(1-D_{0}\right)}{\Delta V_{p v} f_{s w}}
$$

According to this sizing approach, buck converter parameters are listed in Table 2.

Table 2. Buck converter parameters

\begin{tabular}{cc}
\hline Components & Rating values \\
\hline Switching frequency & $f_{s w}=50 \mathrm{kHz}$ \\
Inductance & $L=470 \mu \mathrm{H}$ \\
Input capacitor & $C_{i n}=470 \mu \mathrm{F}$ \\
Nominal input voltage & $95 \mathrm{~V}$ \\
Nominal output voltage & $48 \mathrm{~V}$ \\
\hline
\end{tabular}

Applying the basic Kirchhoff's laws in Figure 1, the system dynamics can be revealed based on CCM operation. When the PV-link voltage is the control variable, the output voltage Vo is assumed to be constant for dynamic modeling. Based on the switching device conduction state $\mathrm{Q}$, we distinguish two cases:

\section{Q on-state Dynamics:}

$$
\begin{gathered}
L \frac{d i_{L}}{d t}=v_{p v}-v_{0} \\
C_{i n} \frac{d v_{p v}}{d t}=i_{p v}-i_{L}
\end{gathered}
$$

\section{Q off-state Dynamics:}

$$
L \frac{d i_{L}}{d t}=-v_{0}
$$




$$
C_{i n} \frac{d v_{p v}}{d t}=i_{p v}
$$

\subsubsection{Dynamic modeling}

The PV output generator and the power conditioning circuits are nonlinear. From the dynamic expression of the switching on/off operation, an averaged model can be derived using the state-space averaging method and linearization technique to derive linear models for dynamic analysis and controller synthesis. The averaging approach requires that switching device frequency is much higher than the system's critical dynamics, which are formed by energy-storage components, such as the capacitor and the inductor. Under this condition, the nonlinear switching dynamics can be neglected for dynamic analysis and controller synthesis. During one switching cycle, the system state-space model can be derived from the on-state and off-state of the power switch. The averaged value of continuous signals can be used to form a dynamic model without the need to represent the switching ripples.

The system dynamics can be expressed in a general form showing the dynamics of the inductor current and the PV-link voltage:

$$
\begin{aligned}
& \frac{d i_{L}}{d t}=f\left(i_{L}, v_{p v}, d\right) \\
& \frac{d v_{p v}}{d t}=g\left(i_{L}, v_{p v}, d\right)
\end{aligned}
$$

The linear model can be derived by a linearization process:

$$
\begin{gathered}
\frac{d i_{L}}{d t}=\left.\frac{\partial f}{\partial v_{p v}}\right|_{S S} \quad v_{p v}+\left.\frac{\partial f}{\partial i_{L}}\right|_{S S} \underset{i_{L}}{\square}+\left.\frac{\partial f}{\partial d}\right|_{S S} \quad \square \\
\frac{d v_{p v}}{d t}=\left.\frac{\partial g}{\partial v_{p v}}\right|_{S S} v_{p v}+\left.\frac{\partial g}{\partial i_{L}}\right|_{S S} \underset{i_{L}}{\square}+\left.\frac{\partial g}{\partial d}\right|_{S S} \quad \square
\end{gathered}
$$

where, $\tilde{l}_{L}, \tilde{v}_{p v}$, and $\tilde{d}$ represent the small signals of the PV module voltage $\mathrm{V}_{\mathrm{pv}}$, the inductor current $i_{L}$, and the switching duty cycle $\mathrm{d}$, and SS denotes the steady state.

Averaging the state dynamics of Eqns. (20), (21), (22), and (23), we get:

$$
\begin{gathered}
\frac{d i_{L}}{d t}=-\underbrace{\frac{1}{L}\left[d v_{p v}-v_{o}\right]}_{f\left(v_{p v}, d, i_{L}\right)} \\
\frac{d v_{p v}}{d t}=-\underbrace{\frac{1}{C_{i n}}\left[d i_{p v}-d i_{L}\right]}_{g\left(v_{p v}, d, i_{L}\right)}
\end{gathered}
$$

where, $d$ is the switching duty cycle and the control variable. Due to the nonlinear characteristics in (28) and (29), linearization is required to derive the small-signal model at the nominal operating condition. Based on the predefined steady state, the small-signal model can be derived using (26) and (27) and expressed in the state-space form as:

$$
\left[\begin{array}{c}
\frac{d i_{L}}{d t} \\
\frac{d v_{p v}}{d t}
\end{array}\right]=\left[\begin{array}{cc}
0 & \frac{D}{L} \\
-\frac{D}{C_{i n}} & \frac{1}{R_{p v} C_{i n}}
\end{array}\right]\left[\begin{array}{c}
\square \\
i_{L} \\
v_{p v}
\end{array}\right]+\left[\begin{array}{c}
\frac{v_{p v}}{L} \\
-\frac{i_{L}}{C_{i n}}
\end{array}\right] d
$$

where, $D, V_{p v}$, and $i_{L}$ are considered to be constant in the steady state. The signals $\tilde{l}_{L}, \tilde{v}_{p v}$ are the state variables and $\tilde{d}$ represent the control variable, $R_{p v}$ is the PV resistance defined as the ratio between PV terminal voltage and current.

\subsection{Battery modeling}

The battery can be considered a variable voltage resource, with the steady-state value affected by the state of charge (SOC) and the rate of charge or discharge. A simple battery model can be represented by a Thévenin equivalent circuit, which is formed by a voltage source in series connection with a resistor, as shown in Figure 1. The model can be configured to simulate the steady-state value of the voltage responding to the discharge current variations, as expressed in Eq. (31).

$$
v_{b a t}=V_{O C}-R_{b a t} \cdot i_{b a t}
$$

BK-10V10T is a specific battery module used in this paper. These parameters are defined in Table 3. Figure 6 illustrates discharge characteristics given by the product datasheet [14].

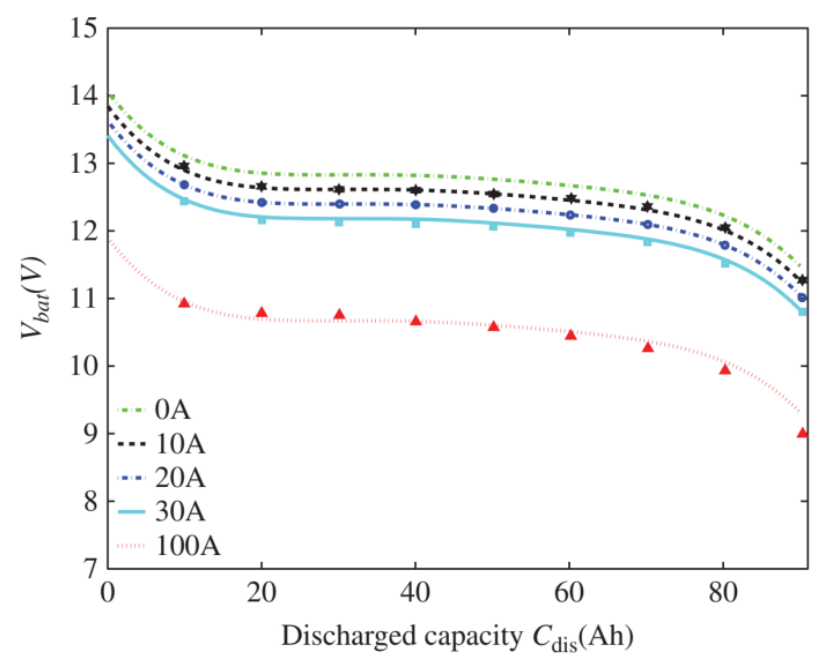

Figure 6. Battery voltages versus discharged capacity for model output and product data

Table 3. DC load and battery parameters

\begin{tabular}{cc}
\hline Components & Rating values \\
\hline Battery type & NiMH \\
Battery model & BK-10V10T \\
Battery pack voltage rating & $55 \mathrm{~V}$ \\
Band of voltage limits & $54.45-55.45 \mathrm{~V}$ \\
Battery pack nominal capacity & $90 \mathrm{Ah}$ \\
Nominal voltage of DC load & $48 \mathrm{~V}$ \\
Acceptable voltage range of DC load & $42-56 \mathrm{~V}$ \\
\hline
\end{tabular}

For a general representation, the discharge capacity, $\mathrm{C}_{\text {dis }}$ can be converted into the SOC, which is the normal way to represent the battery capacity. For the BK-10V10T module, the polynomial function is derived in Eq. (32), where polynomial constants are listed in Table 4. 
Table 4. Polynomial parameters for modeling battery module BK-10V10T

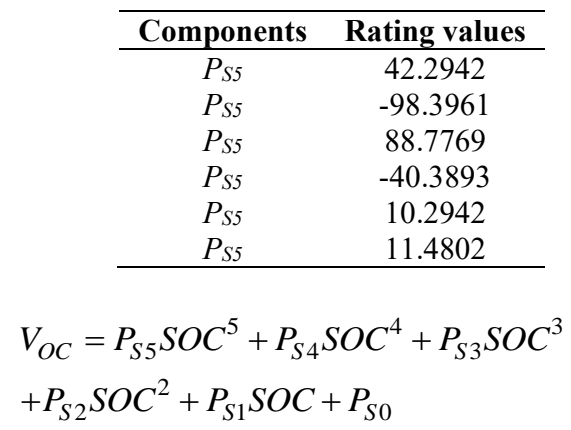

In the equivalent circuit of Figure 1, the inductor current of the buck converter is denoted $i_{L}$. The circuit dynamics are given by Eqns. (33) and (34).

$$
\begin{gathered}
i_{L}+i_{b a t}=C_{B A T} \frac{d v_{b a t}}{d t}+i_{\text {load }} \\
R_{b a t} C_{B A T} \frac{d i_{b a t}}{d t}+i_{\text {bat }}=i_{\text {load }}-i_{L}
\end{gathered}
$$

With the assumption of a constant voltage $V_{O C}$ in the shortterm steady state, the battery-link dynamics can be represented by the transfer function:

$$
i_{b a t}(s)=\frac{i_{\text {load }}-i_{L}}{R_{b a t} C_{B A T} s+1}
$$

\section{VOLTAGE REGULATION IN PV LINK}

We derive from Eq. (30) the following transfer function:

$$
\frac{\square_{p \psi}(s)}{d(s)}=\frac{-\frac{i_{L}}{C_{i n}} s-\frac{D v_{p v}}{L C_{i n}}}{s^{2}-\left(\frac{1}{R_{p v} C_{i n}}\right) s+\frac{D^{2}}{L C_{i n}}}
$$

The transfer function in Eq. (36) represents a second-order system, which can be standardized by Eq. (37):

$$
G_{0}(s)=\frac{k_{0}(\beta s+1)}{s^{2}+2 \xi \omega_{n} s+\omega_{n}^{2}}
$$

where, the undamped natural frequency and damping factor are expressed as $\omega_{n}$ and $\xi$ respectively. We can then derive the coefficients relating to Eq. (36).

$$
\begin{gathered}
\omega_{n}=\frac{D}{\sqrt{L C_{i n}}} \\
\xi=-\frac{\sqrt{L}}{2 D R_{p v} \sqrt{C_{i n}}} \\
k_{0}=-\frac{D v_{p v}}{L C_{i n}}
\end{gathered}
$$

$$
\beta=\frac{L i_{L}}{D v_{p v}}
$$

The relative degree of the Eq. (36) is one because one minimal phase zero is present. We propose to use a standard PID controller to regulate the PV link voltage. The first-order of the desired closed-loop function transfer $F(s)$ is adopted, with the general form:

$$
F(s)=\frac{1}{\alpha s+1}
$$

$\alpha$ is a constant to be defined. The feedback controller can be derived then as:

$$
C(s)=\frac{s^{2}+2 \xi \omega_{n} s+\omega_{n}^{2}}{k_{0} s(\alpha \beta s+\alpha+\beta)}
$$

The PID controller shown in Eq. (43) can be written in a parallel form as:

$$
C(s)=k_{p}+\frac{k_{i}}{s}+\frac{k_{d}}{\tau . s+1}
$$

PID parameters can be derived from Eq. (43) and Eq. (44) as:

$$
\tau=\frac{\alpha \cdot \beta}{\alpha+\beta}
$$

$$
k_{i}=\frac{\omega_{n}^{2}}{k_{0}(\alpha+\beta)}
$$

$$
\begin{gathered}
k_{p}=\frac{2 \zeta \omega_{n}(\alpha+\beta)-\omega_{n}^{2} \alpha \beta}{k_{0}(\alpha+\beta)^{2}} \\
k_{d}=\frac{(\alpha+\beta)^{2}-2 \zeta \omega_{n}(\alpha+\beta) \alpha \beta+\omega_{n}^{2} \alpha^{2} \beta^{2}}{k_{0}(\alpha+\beta)^{3}}
\end{gathered}
$$

The PID controller for the voltage regulation of the PV link is synthesized and expressed as:

$$
C(s)=-0.0017-\frac{8.4736}{s}-\frac{6.8485 \times 10^{-6}}{2.8745 \times 10^{-4} s+1}
$$

\subsection{Relative stability}

To evaluate the relative stability, the phase margin and gain margin are measured by Bode diagram plot of $C(s) G_{O}(s)$ in the frequency domain as shown in Figure 7 . The value of the gain margin is $8.202(\mathrm{~dB})$ at the frequency of $3500 \mathrm{rad} / \mathrm{s}$, and the phase margin is calculated as $95.67^{\circ}$ at the frequency of $500(\mathrm{rad} / \mathrm{s})$. The closed-loop stability is then proved since both margins are positive.

\subsection{Robustness}

In a closed-loop system, the sensitivity function is defined and expressed as: 


$$
S(s)=\frac{1}{1+C(s) G_{0}(s)}
$$

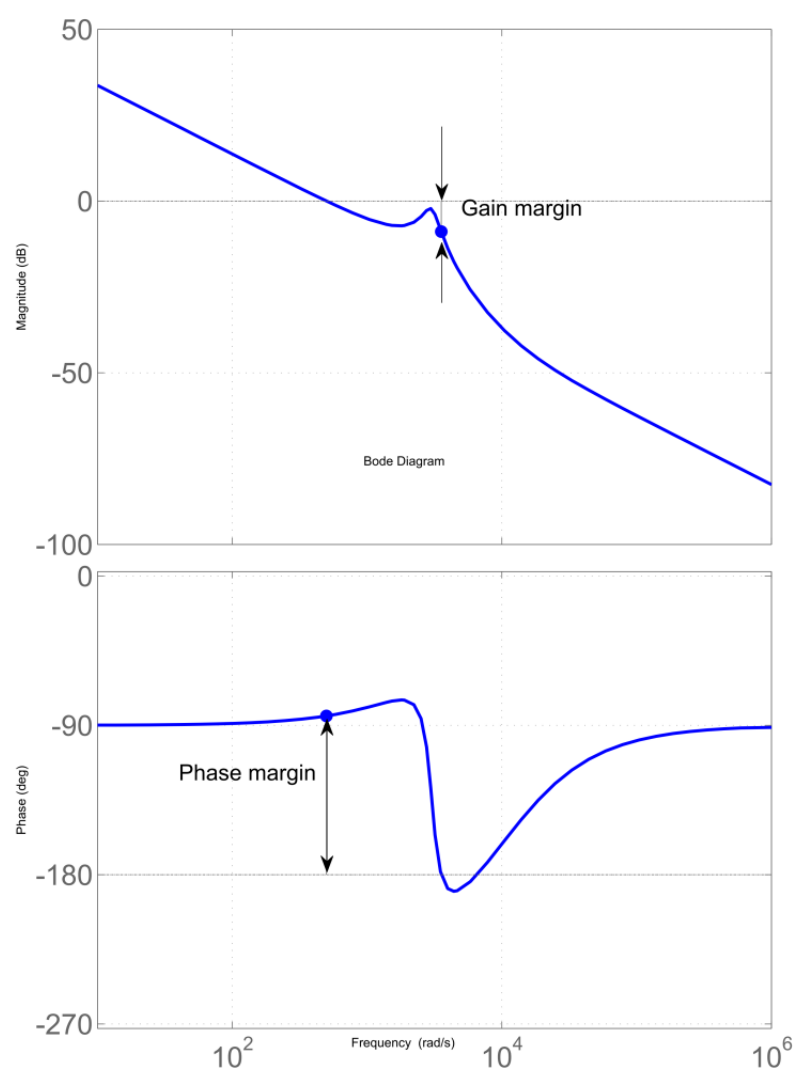

Figure 7. Demonstration of relative stability by Bode diagram

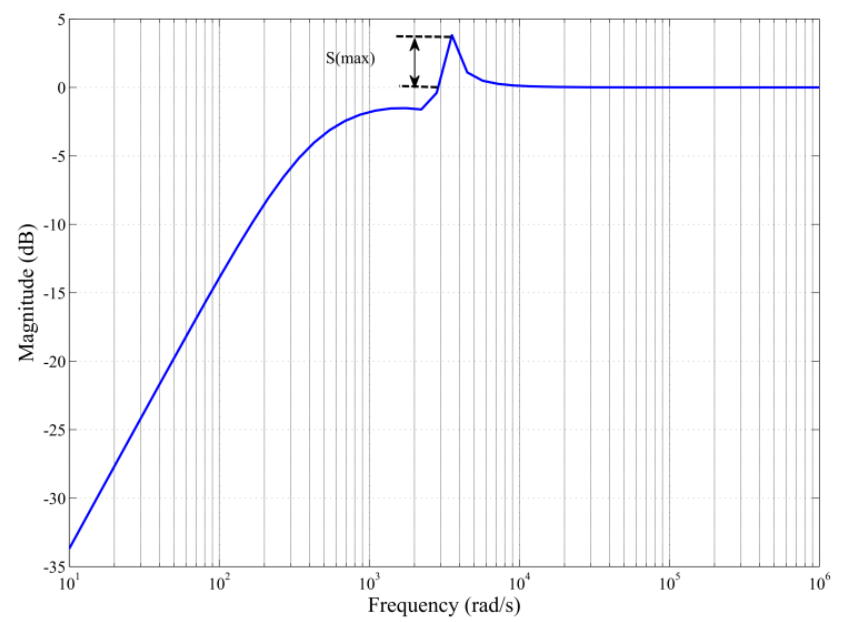

Figure 8. Demonstration of sensitivity by Bode diagram

The sensitivity function is illustrated by a Bode diagram, as shown in Figure 8. The function shows high-pass features: the magnitude is high in the high-frequency band, but is low in the low-frequency band. The magnitude of the sensitivity peak should be lower than 2 to achieve robust system control. The sensitivity peak is specified as the maximum magnitude in $S(s)$ :

$$
S(\max )=\max |S(j \omega)|
$$

The peak gain is measured as 1.5515 and calculated as $3.8153 \mathrm{~dB}$ which guarantees robust operation.

\section{MAXIMUM POWER POINT TRACKING}

In a steady state of cell temperature and solar irradiance, there is a single operating point where the output of the voltage and current results in the maximum power output (MPP). Various techniques have been proposed for the MPPT algorithm. Hill Climbing (HC) technique is one of the most well-known algorithms thanks to its simplicity; even there are oscillations around the MPP in a steady state and a loss of research of the MPP, when climatic conditions change rapidly [15]. This method consists to climb the operating point along with the generator characteristic to a maximum. The output PV power $\mathrm{P}_{\mathrm{New}}$ is periodically compared to the previous value $P_{\text {old }}$. Depending on the outcome of the comparison, we increase or decrease the voltage reference, to calculate the corresponding duty cycle $d$ via the PID regulator. Once the PPM point is reached, the system oscillates around it indefinitely. The flowchart of this algorithm is illustrated in Figure 9.

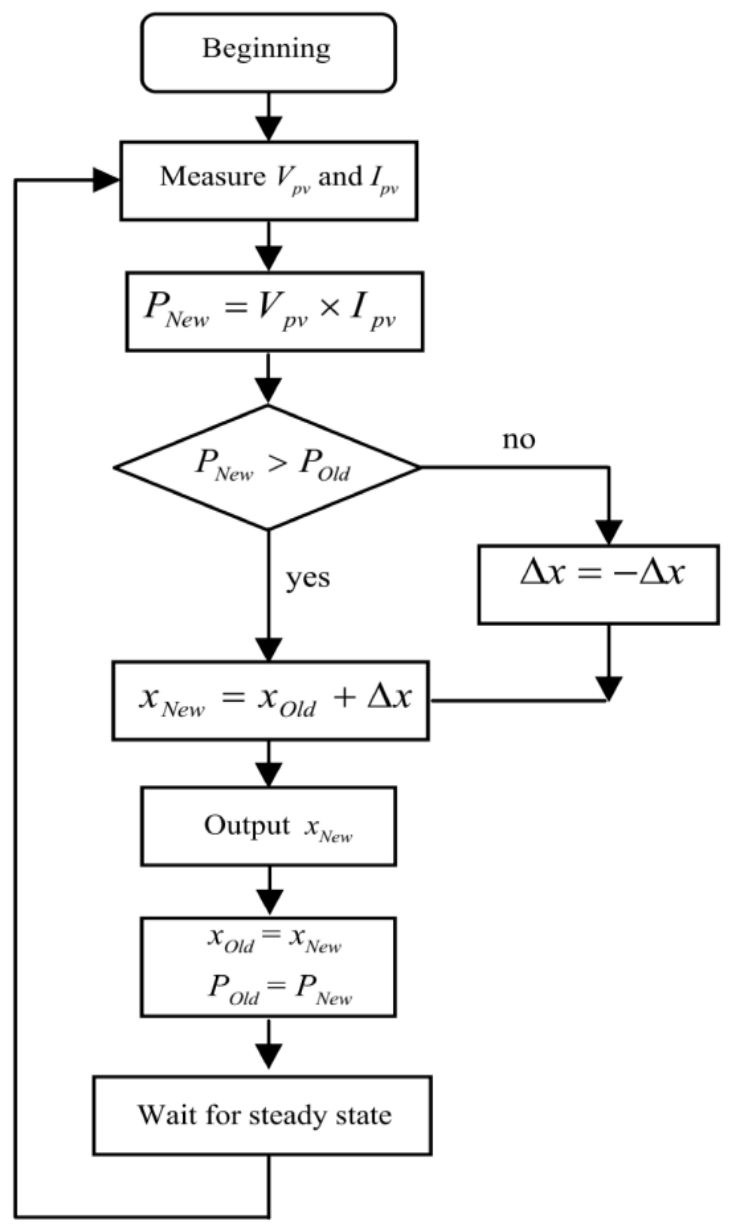

Figure 9. Hill climbing algorithm for maximum power point tracking

\subsection{Integrating battery-charge control with MPPT}

To stop the PV generation from overloading the charging capacity, the charging cycle should be maintained with an MPPT function. When the voltage and current of the battery reach their charging-cycle limits, MPPT should be stopped to reduce $\mathrm{PV}$ power generation. Instead, the control action should shift the operating point of the PV generator in the open-circuit voltage direction or into the voltage-source zone. The rated value and allowable range of voltage variations of the considered battery are given in Table 3 . 


\section{SIMULATION RESULTS}

The overarching model of simulation for the designed system is displayed in Figure 10. It includes the PV array, DC/DC buck converter, battery link, and battery pack, with control and MPPT blocs. To validate the model, we subject it to certain conditions of load change and climatic conditions. Simulation results are illustrated in Figure 11.

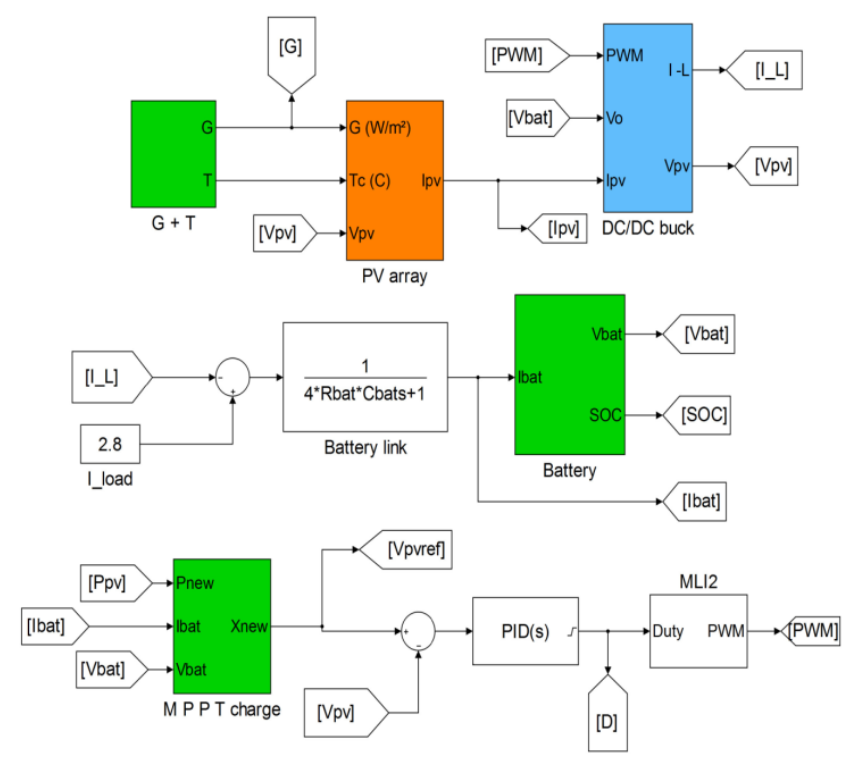

Figure 10. Simulation model of the PV system
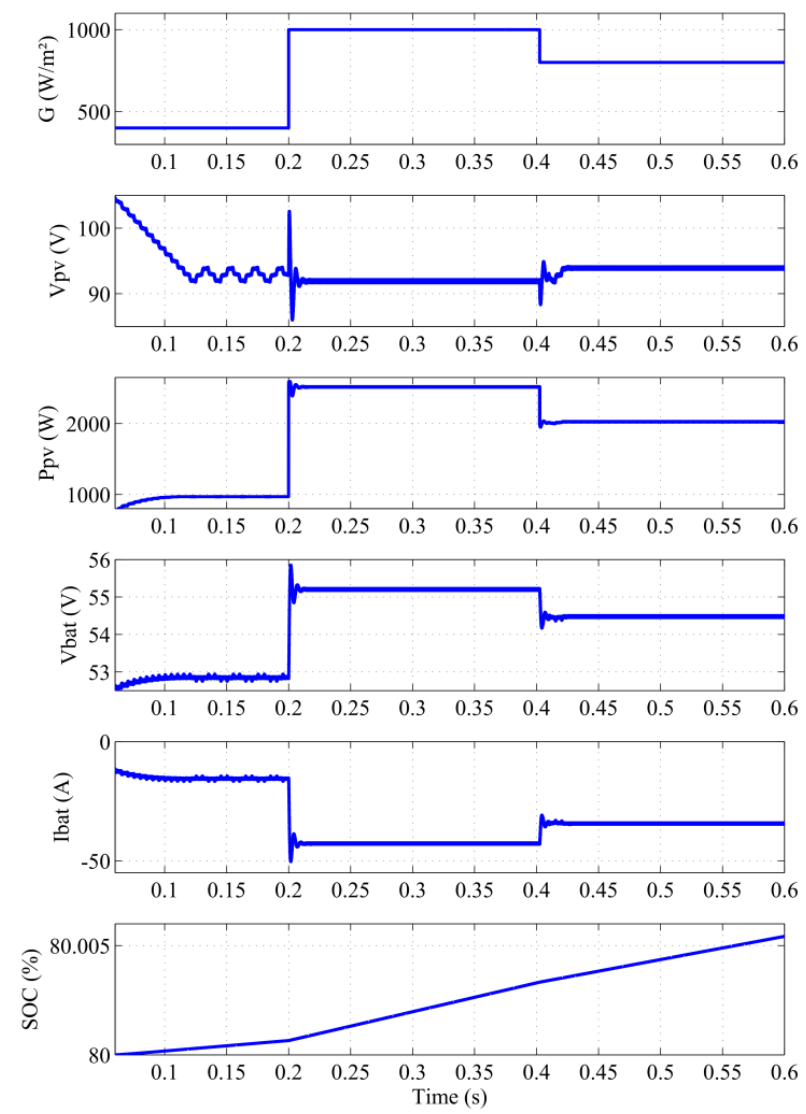

Figure 11. Simulation results

The initial SOC of the battery pack was set to be $80 \%$. A load current of 2.8 was constantly extracted from the battery link. Before $0.2 \mathrm{~s}$, the irradiance was $400 \mathrm{~W} / \mathrm{m}^{2}$ and the cell temperature was $25^{\circ} \mathrm{C}$. Since the voltage is lower than the limit of $54.45 \mathrm{~V}$, the MPP is tracked at $0.09 \mathrm{~s}$ during the start-up period and maintained by the steady-state tracking operation. The voltage ripple caused by the active perturbation of the $\mathrm{HC}$ algorithm is noticeable. The SOC gradually increases in response to the charging current. The solar irradiance steps up at the instant $0.2 \mathrm{~s}$ from 400 to $1000 \mathrm{~W} / \mathrm{m}^{2}$ and steps down again to reach the value $800 \mathrm{~W} / \mathrm{m}^{2}$ at the instant $0.4 \mathrm{~s}$. The PV output power significantly increases, causing an increase in the charging current. The increase of the SOC becomes faster than before. Since the SOC is still relatively low, the battery voltage is still below the upper limit. The MPPT operates continuously to inject the highest power into the battery link.

\section{CONCLUSIONS}

In this paper, a standalone photovoltaic system with energy storage was designed and dimensioned according to the load specifications, the photovoltaic production unit, and the battery pack. Since the PV generator output and the power conditioning circuits are nonlinear, an averaged model was derived for dynamic analysis and controller synthesis, using the state-space averaging and linearization method. Using a specific method, both MPPT function and battery cycle charge were integrated, to achieve the maximum energy and specify the battery voltage to match the load voltage rating. The battery simulation was built using a practical model design. Due to computational constraints, the Simulink model for the controller and power interface is developed only in short term to capture the transient details of fast dynamics, including fast switching in the DC/DC converter. The accuracy of the parameters identified and used in the mathematical models is cheeked by comparing manufacturer's data in tables with simulation results at STC conditions, that show PV power, voltage, and current at MPP, battery voltage regulation, and variation of SOC in response to changes in solar irradiance and cell temperature

\section{REFERENCES}

[1] Khatib, T., Elmenreich, W. (2016). Modeling of Photovoltaic Systems Using Matlab: Simplified Green Codes. John Wiley \& Sons.

[2] Bellia, H., Youcef, R., Fatima, M. (2014). A detailed modeling of photovoltaic module using MATLAB. NRIAG Journal of Astronomy and Geophysics, 3(1): 5361. https://doi.org/10.1016/j.nrjag.2014.04.001

[3] Alsayid, B., Jallad, J. (2011). Modeling and simulation of photovoltaic cells/modules/arrays. International Journal of Research and Reviews in Computer Science, 2(6): 1327-1331.

[4] Huang, P.H., Xiao, W., Peng, J.C.H., Kirtley, J.L. (2015). Comprehensive parameterization of solar cell: Improved accuracy with simulation efficiency. IEEE Transactions on Industrial Electronics, 63(3): 1549-1560. https://doi.org/10.1109/TIE.2015.2498139

[5] Walker, G. (2001). Evaluating MPPT converter topologies using a MATLAB PV model. Journal of Electrical \& Electronics Engineering, Australia, 21(1): 49-55.

[6] Zerhouni, F.Z., Zerhouni, M.H., Zegrar, M., 
Benmessaoud, M.T., Stambouli, A.B., Midoun, A. (2010). Proposed methods to increase the output efficiency of a photovoltaic (PV) system. Acta Polytechnica Hungarica, 7(2): 55-70.

[7] Mouhadjer, S., Chermitti, A., Neçaibia, A. (2012). Comprehensive and field study to design a buck converter for photovoltaic systems. Revue des Energies Renouvelables, 15(2): 321-330.

[8] Precup, R.E., Kamal, T., Hassan, S.Z. (Eds.). (2019). Solar Photovoltaic Power Plants: Advanced Control and Optimization Techniques. Springer.

[9] Zainudin, H.N., Mekhilef, S. (2010). Comparison study of maximum power point tracker techniques for PV systems. Proceedings of the 14th International Middle East Power Systems Conference (MEPCON'10), Cairo University, Egypt, Cairo University, Egypt.

[10] Du, Y., Li, X., Wen, H., Xiao, W. (2015). Perturbation optimization of maximum power point tracking of photovoltaic power systems based on practical solar irradiance data. 2015 IEEE 16th Workshop on Control and Modeling for Power Electronics (COMPEL), Vancouver, BC, Canada, pp. 1-5. https://doi.org/10.1109/COMPEL.2015.723650.

[11] Altas, I.H., Sharaf, A.M. (2008). A novel maximum power fuzzy logic controller for photovoltaic solar energy systems. Renewable Energy, 33(3): 388-399. https://doi.org/10.1016/j.renene.2007.03.002

[12] Ramaprabha, R., Mathur, B.L. (2011). Intelligent controller based maximum power point tracking for solar PV system. International Journal of Computer Applications, $\quad$ 12(10): 37-41. https://doi.org/10.5120/1717-2303

[13] Xiao, W. (2017). Photovoltaic Power System: Modeling, Design, and Control. John Wiley \& Sons.

[14] Panasonic Industry Nickel Hybrid Battery. (2020).
https://industrial.panasonic.com/content/data/BT/docs/e dbd/ni_mh/Introduction of Nickel Metal Hydride Battery_Web_20200203.pdf.

[15] Rekioua, D., Matagne, E. (2012). Optimization of photovoltaic power systems: Modelization, simulation and control. Springer Science \& Business Media.

\section{NOMENCLATURE}

$G \quad$ Solar irradiance, $\mathrm{W} / \mathrm{m}^{2}$

$I_{M} \quad$ Instant MPP current, A

$i_{p h} \quad$ PV photon current, A

$i_{p v} \quad$ PV cell output current, A

$I_{d} \quad$ Diode current, $\mathrm{A}$

$I_{S S} \quad$ Diode reverse-bias saturation current, A

$T_{C} \quad$ PV cell temperature, $\mathrm{K}$

$V_{D} \quad$ Diode voltage, $\mathrm{V}$

$V_{M} \quad$ Instant MPP voltage, $\mathrm{V}$

$V_{O C} \quad$ PV open-circuit voltage, $\mathrm{V}$

$V_{P V} \quad$ PV cell terminal voltage, $\mathrm{V}$

$V_{t} \quad$ Thermal voltage of $\mathrm{p}-\mathrm{n}$ junction, $\mathrm{V}$

$\alpha_{T} \quad$ dimensionless temperature coefficient on PV current

$\beta_{T} \quad$ dimensionless temperature coefficient on PV voltage

$\lambda_{T}$ dimensionless irradiance coefficient on PV power

$A_{n} \quad$ dimensionless, diode ideality factor in SDM

$I_{M S} \quad$ PV current at MPP and STS, A

$I_{p h} \quad$ PV photon current at STC, A

$I_{S C S} \quad$ PV short-circuit current at the STC, A

$I_{S} \quad$ Diode reverse-bias saturation current, A

$P_{M P P} \quad$ PV power at MPP and STC, W

$R_{S} \quad$ Series resistance, $\Omega$

$R_{h} \quad$ Shunt resistance, $\Omega$

$V_{M S} \quad$ PV voltage at MPP and STC, V

$V_{O C S}$ PV open-circuit voltage at STC, V 